\title{
Electrophoretic deposition of titania nanoparticles: Wet density of deposits during EPD
}

\author{
MORTEZA FARROKHI-RAD*, TAGHI SHAHRABI and SHIRIN KHANMOHAMMADI \\ Department of Materials Science and Engineering, Tarbiat Modares University, P.O. Box 14115-143, Tehran, Iran
}

MS received 22 July 2013; revised 20 October 2013

\begin{abstract}
Electrophoretic deposition (EPD) of titania nanoparticles was performed at different voltages and times. The wet density of deposits was calculated according to the Archimedes' principle. The wet density as well as the electric field over the deposits increased with time and attained the plateau at longer times. The velocity at which particles attach to the deposit, strongly influences its wet density at initial times. However, the effect of electro-osmotic flow is dominant at longer times. The coating with higher wet density had the higher corrosion resistance in Ringer's solution at $37.5^{\circ} \mathrm{C}$ due to its closely packed and crack free microstructure.
\end{abstract}

Keywords. Electrophoretic deposition (EPD); electro-osmotic flow; titania nanoparticles; triethanolamine (TEA); wet density.

\section{Introduction}

In recent years, electrophoretic deposition (EPD) has been widely used to deposit titania nanostructured coatings (Yui et al 2005; Tang et al 2006; Grinis et al 2008; Kawakita et al 2009; Farrokhi-Rad and Ghorbani 2011). EPD has several advantages such as simplicity, need to low-cost equipments, no limitation in the substrate shape, easy control of the coating thickness and so on (Besra and Liu 2007). Another important advantage of EPD is its ability to manipulate the microstructure of deposit by simple adjustment of EPD parameters. For example, the packing density of particles and so the amount of porosity in deposit can be controlled by adjusting the deposition voltage and time. The coatings with high level of porosity are desired for some applications; for example, the implant coatings with high level of interconnected porosities are beneficial for effective bone ingrowths into these pores (Cook et al 1992; Hench 1998; Kienapfel et al 1999; Nguyen et al 2004); or the catalytic efficiency increases with increasing the porosity (surface area) of catalyst coatings ( $\mathrm{Yu}$ et al 2000; Agrafiotis and Tsetsekou 2002; Yusuf et al 2002). However, the coatings with high-packing density or low level of porosity are acceptable in some other applications; for example, protective coatings or the coatings undergoing high level of mechanical loading must have the minimum amount of porosity in their microstructure (Kulkarni et al 2004). The amount of porosity in sintered EPD coatings is highly dependent on the amount of original porosity

\footnotetext{
*Author for correspondence (morteza_farrokhi_rad@yahoo.com)
}

present in their green state. The amount of porosity in green state is dependent on the order of particles arrangement and rearrangement in deposit during EPD. Basu et al (2001) found that particles move so fast towards the substrate electrode at high applied electric fields, so that they cannot find enough time to sit in their best position to form a close-packed microstructure. The velocity of particles during EPD can be obtained by the following equation (Smoluchowski 1917)

$$
v=\mu E \text { and } \mu=\frac{\varepsilon_{0} \varepsilon_{\mathrm{r}} \zeta}{\eta},
$$

where $\mu$ is the electrophoretic mobility of particles, $E$ the applied electric field, $\zeta$ the zeta potential of particles, $\varepsilon_{0}$ the permittivity of vacuum, $\varepsilon_{\mathrm{r}}$ the relative dielectric constant of medium and $\eta$ the viscosity of solvent.

Bohmer (1996) observed in situ using optical microscopy that micron-sized latex particles deposited on the electrode with opposite charge aggregated to form largeordered clusters during EPD. Such aggregation phenomenon can be explained by electro-osmotic flow around the particles in deposit during EPD (Solomentsev et al 1997; Yeh et al 1997). The velocity of electro-osmotic flow $\left(v_{\mathrm{E} . \mathrm{O}}\right)$ can be obtained by the following equation (Solomentsev et al 1997)

$$
v_{\mathrm{EO}}=\frac{\varepsilon_{0} \varepsilon_{\mathrm{r}} \zeta}{\eta} E_{\mathrm{dep}},
$$

where $E_{\text {dep }}$ is the electric field over the deposit.

Ji et al (2008) electrophoretically-deposited the yttriastabilized zirconia coatings and found that the packing 
density of wet deposits decreases with the increase in the deposition voltage and time. They also increased the packing density of deposits by immersing the wet deposits in pure acetylacetone and applying the constant d.c. electric field between substrate and counter electrodes; they explained this densification process by the electroosmotic flow around the particles in deposit. According to the above explanations, increasing the applied electric field has a dual effect on the packing density of particles in the deposits formed by EPD: on one hand, it decreases the packing density by disordering the particles arrangement in deposit, and on the other hand, it increases the packing density by intensifying the electro-osmotic flow around the particles in deposit.

The aim of the present work is to study the effect of different EPD parameters such as deposition voltage and time and suspension properties such as zeta potential of particles on the wet density of deposits calculated by the Archimedes’ principle.

\section{Experimental}

\subsection{Suspensions preparation}

Titania nanopowder (99.5\%, P25, Degussa, Germany) with an average particle size of $21 \mathrm{~nm}$ was used. Isopropanol (99.8\%, Merck Co., Germany) and triethanolamine (TEA, reagent grade, Merck Co., Germany) were used as solvent and dispersant, respectively. To prepare the suspension, first, TEA was added at different concentrations $(0,0 \cdot 33,4,8$ and $16 \cdot 33 \mathrm{~mL} / \mathrm{L})$ into the isopropanol and stirred for $15 \mathrm{~min}$. Then, titania nanoparticles with the concentration of $20 \mathrm{~g} / \mathrm{L}$ were added into them. The suspensions were stirred magnetically and dispersed ultrasonically (20 kHz, Sonopuls HD 3200, Bandelin Co., Germany) for $24 \mathrm{~h}$ and $10 \mathrm{~min}$, respectively. The operational pH (744 pH meter, Metrohm, Herisau, Switzerland) and the zeta potential of particles was measured (Malvern Instruments, UK) against TEA concentration. Prior to zeta potential measurement, the suspensions were diluted according to the method described in reference (Farrokhi-Rad and Ghorbani 2011).

\subsection{Electrophoretic deposition}

A two-electrode cell with the electrode distance of $1 \mathrm{~cm}$ was used. The plates of $316 \mathrm{~L}$ stainless steel with the dimension of $40 \times 20 \times 1 \mathrm{~mm}$ (only $4 \mathrm{~cm}^{2}$ of substrates exposed to deposition) were used as the substrate electrode. A 316L stainless steel plate with the same dimension of the substrate electrode was used as a counter electrode. EPD was performed at 60 and $200 \mathrm{~V}$ using a laboratory power supply (HY30002E, Huayi Electronics Industry Co., China) for 15, 30, 120, 240 and $360 \mathrm{~s}$ (each EPD experiment was performed 4 times). The current density during EPD was recorded by a computer connected digital multimeter (Fluke, 289 True RMS, USA). The wet weight of deposits $\left(W_{\text {wet }}\right)$ was measured immediately after EPD, using a $0.1 \mathrm{mg}$ accuracy balance (GR200, A\&D Co., Tokyo, Japan). EPD was performed on 3 samples in the similar experimental conditions. The measurements were carried out at room temperature $\left(25^{\circ} \mathrm{C}\right)$ and atmospheric pressure. The immersion weight of deposits ( $\left.W_{\text {imm }}\right)$ was recorded in situ according to the method described in Farrokhi-Rad and Shahrabi (2012). The wet density ( $\rho_{\text {wet }}$ ) of deposits at moment $t$ was calculated using the following equation

$$
\rho_{\text {wet, } \mathrm{t}}=\frac{W_{\text {wet, } \mathrm{t}}}{V o l_{\text {wet, }}} \quad \text { and } \quad V o l_{\text {wet }, \mathrm{t}}=\frac{W_{\text {wet, }}-W_{\text {imm,t }}}{\rho_{\text {ISP }}} \text {, }
$$

where $V o l_{\text {wet,t }}$ is the wet volume of the deposit and $\rho_{\text {ISP }}$ the density of isopropanol $\left(0.78 \mathrm{~g} \mathrm{~cm}^{-3}\right)$.

The electric field over the deposit at any moment $\left(E_{\mathrm{dep}, \mathrm{t}}\right)$ was calculated by the following equation

$$
E_{\text {dep,t }}=\frac{V_{\text {dep,t }}}{d_{\text {dep.t }}}
$$

and

$$
\left(V_{\text {dep,t }}=V_{\text {app }}-R_{\text {sus }} \cdot i_{\mathrm{t}}, d_{\text {dep }, \mathrm{t}}=\frac{V o l_{\text {wet, }}}{A_{\text {sub }}}\right),
$$

where $V_{\text {dep,t }}$ is the voltage drop over the deposit, $V_{\text {app }}$ the applied voltage (60 and $200 \mathrm{~V}$ ), $R_{\text {sus }}$ the electrical resistance of the suspension (which is assumed to be constant with time and calculated by dividing the applied voltage by the current passing through the EPD circuit at initial times), $i_{\mathrm{t}}$ the current passing through the circuit at moment $t, d_{\text {dep,t }}$ the thickness of the wet deposit at moment $t$ and $A_{\text {sub }}$ the deposition area of the substrate electrode $\left(4 \mathrm{~cm}^{2}\right)$. The thickness of the dry deposits was measured using a coating thickness gauges (Qnix 8500, Germany). The microstructure of the coatings was observed by optical and scanning electron microscope (SEM).

The effect of titania coatings on the corrosion resistance of substrate in Ringer's solution at $37.5{ }^{\circ} \mathrm{C}$ was investigated by potentiodynamic polarization technique

Table 1. $\mathrm{pH}$ of the suspensions and zeta potential of titania nanoparticles for the suspensions with different concentrations of TEA.

\begin{tabular}{llc}
\hline $\begin{array}{l}\text { TEA concentration } \\
(\mathrm{mL} / \mathrm{L})\end{array}$ & $\mathrm{pH}$ & $\begin{array}{c}\text { Zeta potential } \\
(\mathrm{mV})\end{array}$ \\
\hline 0 & $5 \cdot 82$ & $41 \cdot 51$ \\
$0 \cdot 33$ & 7 & $75 \cdot 78$ \\
$1 \cdot 33$ & $7 \cdot 76$ & $59 \cdot 54$ \\
4 & $8 \cdot 21$ & $35 \cdot 66$ \\
8 & $8 \cdot 27$ & $34 \cdot 16$ \\
$16 \cdot 33$ & $8 \cdot 66$ & $33 \cdot 56$ \\
\hline
\end{tabular}



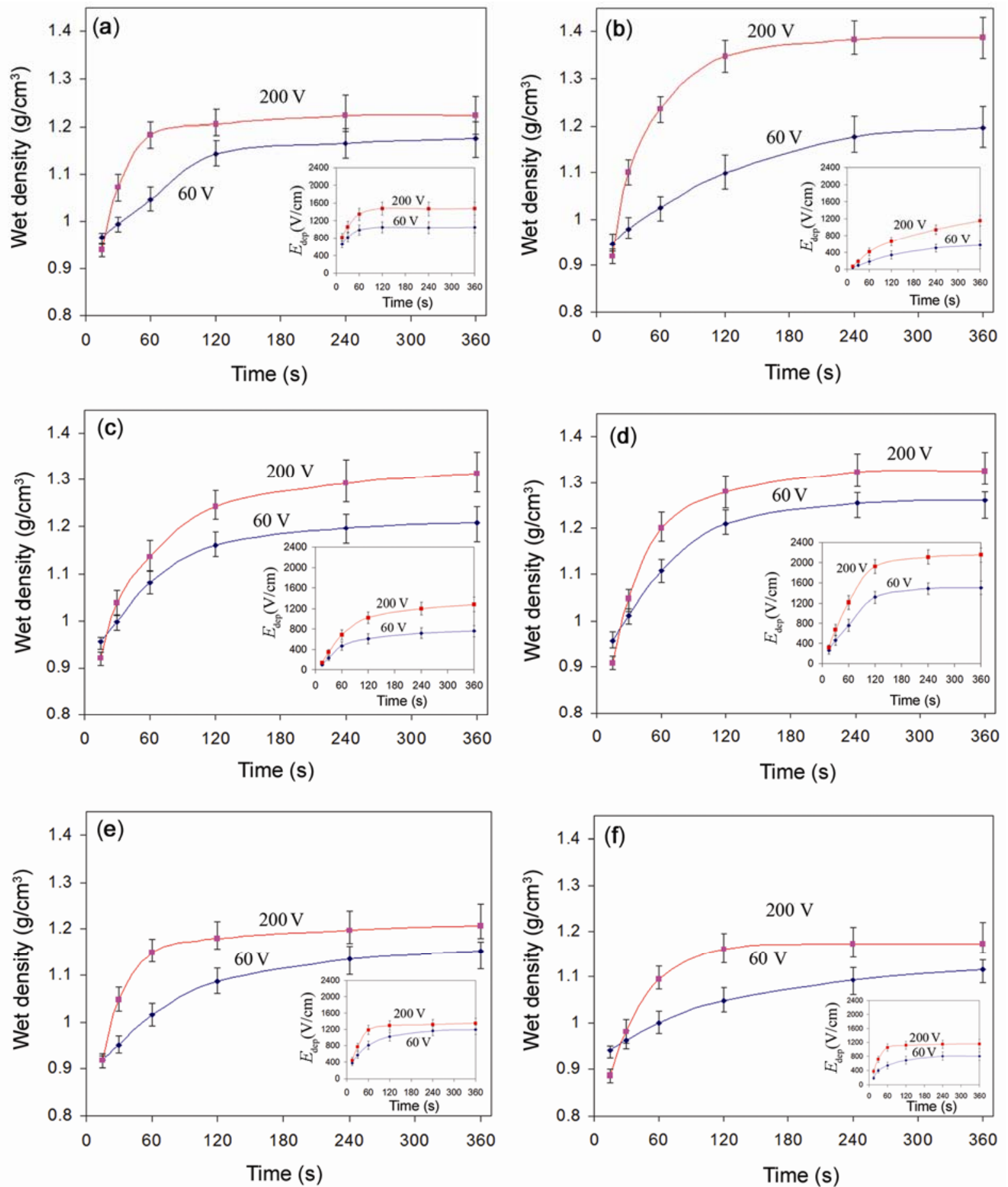

Figure 1. Wet density of deposit formed at 60 and $200 \mathrm{~V}$ from the suspensions containing different concentrations of TEA ((a) 0, (b) 0.33, (c) 1.33, (d) 4, (e) 8 and (f) $16.33 \mathrm{~mL} / \mathrm{L}$ ) vs time (inset figures show electric field over the deposit against time at 60 and $200 \mathrm{~V})$.

(potentiostat/galvanostat Autolab 84367). A threeelectrode cell was used for potentiodynamic polarization tests. Uncoated (bare substrate) and titania-coated substrates were used as working electrode. Saturated calomel electrode (SCE) and a platinum wire mesh were used as reference and counter electrodes, respectively (scan rate: $1 \mathrm{mV} / \mathrm{s})$.

\section{Results and discussion}

The results for the $\mathrm{pH}$ of the suspensions and zeta potential of titania nanoparticles in the suspensions with different concentrations of TEA are listed in table 1. TEA has alkaline characteristics due to a lone pair of electrons in nitrogen atoms; so the $\mathrm{pH}$ of suspension continuously 
(a) $60 \mathrm{~V}$

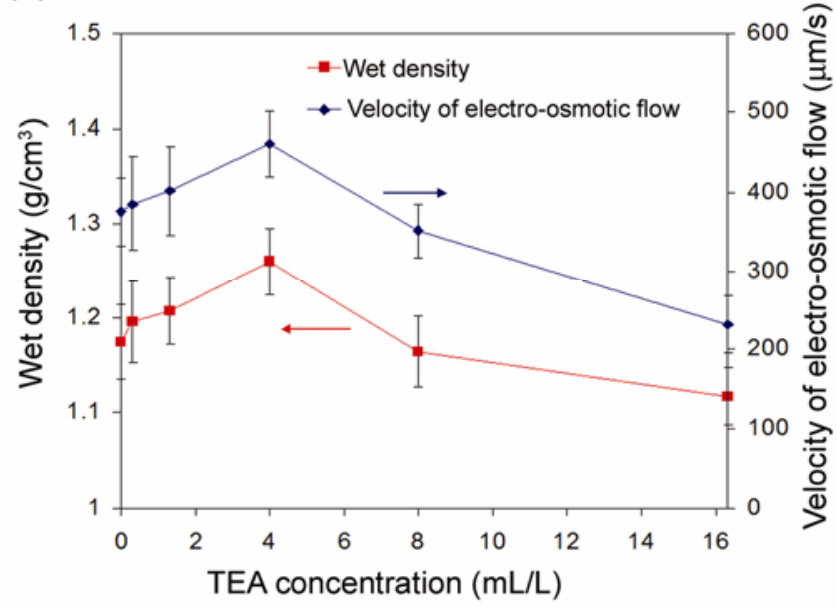

(b) $200 \mathrm{~V}$

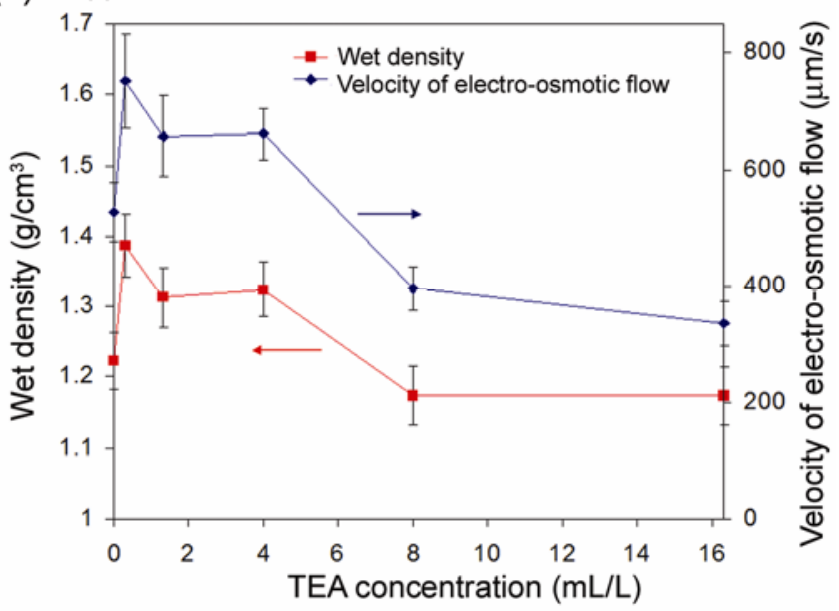

Figure 2. Wet density of deposits and velocity of electro-osmotic flow against TEA concentration at (a) 60 and (b) $200 \mathrm{~V}$ and longer EPD times (360 s).

increases with TEA concentration. The detailed discussion explaining the mechanism of zeta potential variation against TEA concentration has been reported in our previous work (Farrokhi-Rad and Shahrabi 2012).

The wet density is referred to the density of the asprepared wet deposit consisting of titania nanoparticles and interparticles suspension medium (isopropanol) between them. Figure 1 shows the results for the wet density (calculated using (3)) of the deposits formed at 60 and $200 \mathrm{~V}$ from the suspensions with different TEA concentrations against deposition time. The results for electric field over the deposits (calculated using (4)) as a function of deposition time are also shown as insets in figure 1 . As can be seen in figure 1 , the wet density of deposits increases with time at both deposition voltages and attains a plateau at longer times. Also, the wet density increases faster at $200 \mathrm{~V}$ than $60 \mathrm{~V}$. As can be seen in inset figures, the electric field over the deposits (and so the velocity of electro-osmotic flow (2)) exhibits the similar behaviour as the wet density.

As mentioned previously, the wet density of deposits at any moment of EPD is attributed to the order of particles arrangement as well as their rearrangement in deposit during EPD. The $E_{\text {dep }}$ has small values at initial times of EPD and its values are nearly equal for 60 and $200 \mathrm{~V}$; so the effect of disordering the particles arrangement in deposit is dominant at initial times of EPD, so that the wet density decreases as the deposition voltage increases (as can be seen in figure 1 at $15 \mathrm{~s}$, the wet density of the deposits formed at $60 \mathrm{~V}$ is higher than that of those formed at $200 \mathrm{~V}) . E_{\text {dep }}$ increases with time at both 60 and $200 \mathrm{~V}$ (figure 1 (inset figures)), increasing the velocity of electro-osmotic flow and so the wet density of deposit by intensifying the particles rearrangement in it. On the other hand, the deposits thicken with time increasing the voltage drop over it; so the effective electric field present across the suspension and accelerate particles towards the electrode with opposite charge (and so the velocity of particles) decreases with time. As mentioned previously, particles moving at slower velocities have longer time to sit in the best position in the deposit yielding the highest wet density for it. $E_{\text {dep }}$ increases more steeply with time at $200 \mathrm{~V}$ than $60 \mathrm{~V}$ (figure 1 (inset figures)); so, the effect of electro-osmotic flow becomes more prominent with time at $200 \mathrm{~V}$ and the wet density increases more steeply in it.

The calculated results obtained for the wet density of the deposits formed at 60 and $200 \mathrm{~V}$ for $360 \mathrm{~s}$ from the suspensions with the different concentrations of TEA as well as the velocity of electro-osmotic flow within them, are presented in figure 2. As it was observed in figure 1, the wet density and the electric field over the deposit (and so the velocity of electro-osmotic flow (2)) attain the plateau at longer EPD times; so the relationship between the wet density and the velocity of electro-osmotic flow can be studied more accurately at longer EPD times. As can be seen in figure 2, there is a good agreement between the trend of changes in the values of wet density and the values of the velocity of electro-osmotic flow, so that the deposits formed from the suspensions with 4 and $0 \cdot 33 \mathrm{~mL} / \mathrm{L}$ TEA have the maximum values of wet density as well as the maximum values of the velocity of electroosmotic flow at 60 and $200 \mathrm{~V}$, respectively.

The thickness of wet and dry deposits prepared at 60 and $200 \mathrm{~V}$ from the suspensions with different concentrations of TEA are shown in figure 3. As it is expected, the thickness of dry deposits is considerably smaller than that of wet deposits. Also, it can be seen that the difference between the thickness of wet and dry deposits is smaller for those with higher wet density (for instance, the deposits formed at $200 \mathrm{~V}$ from the suspension with $0.33 \mathrm{~mL} / \mathrm{L}$ TEA). The drying shrinkage is less for the 

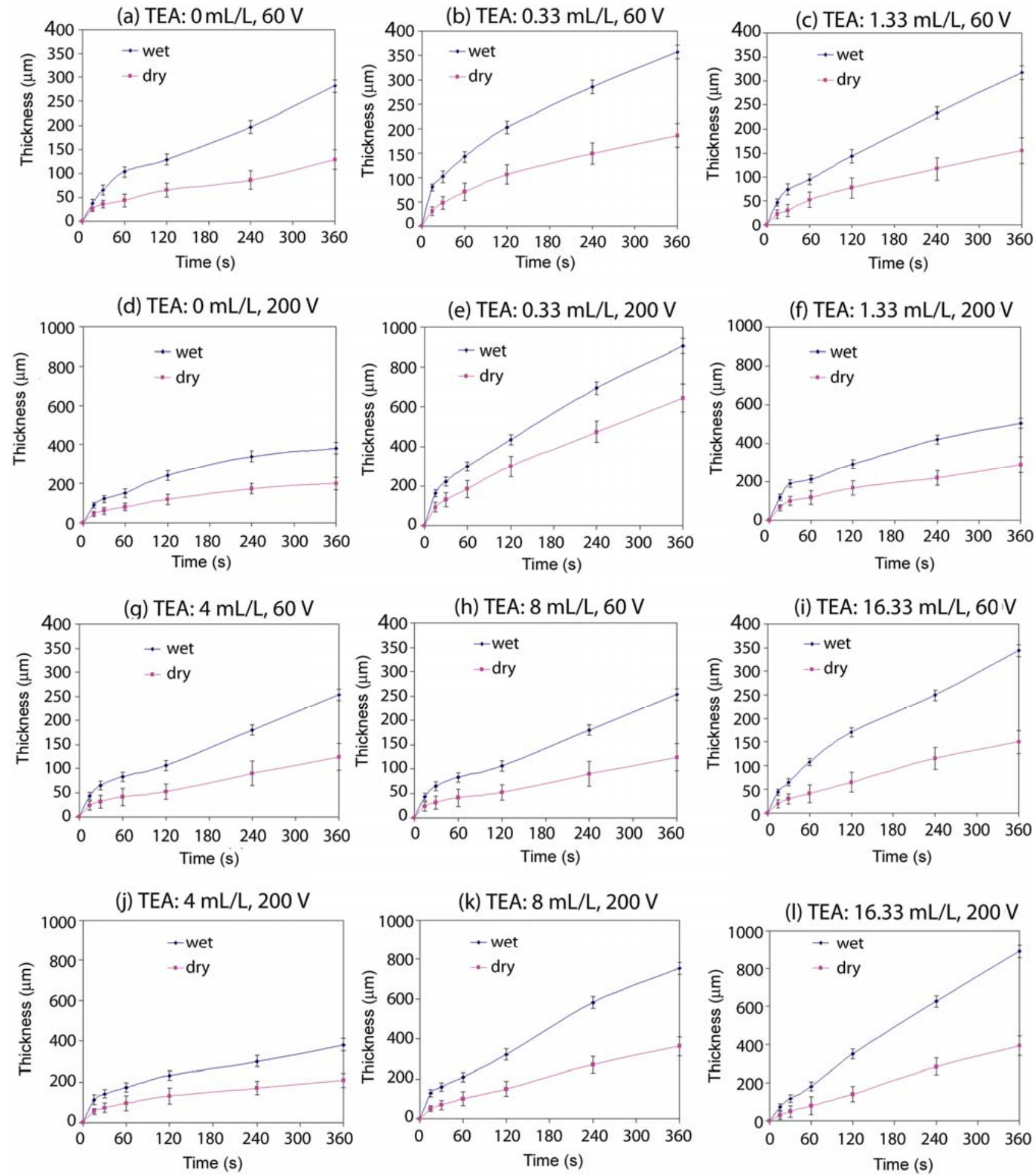

Figure 3. Thickness of wet and dry deposits prepared at 60 and $200 \mathrm{~V}$ from the suspensions with different concentrations of TEA against time.

deposits with higher wet density (due to lower liquid content in the deposit) resulting in the less difference between their wet and dry thicknesses (smaller shrinkage also prevent from crack formation during drying (figure 6)).
SEM images of the coatings deposited at $60 \mathrm{~V}$ for $30 \mathrm{~s}$ from the suspensions with different concentrations of TEA are shown in figure 4. As can be seen in figure 4, SEM images have a good agreement with calculated values for the wet density of deposits, so that the particles 
(a)

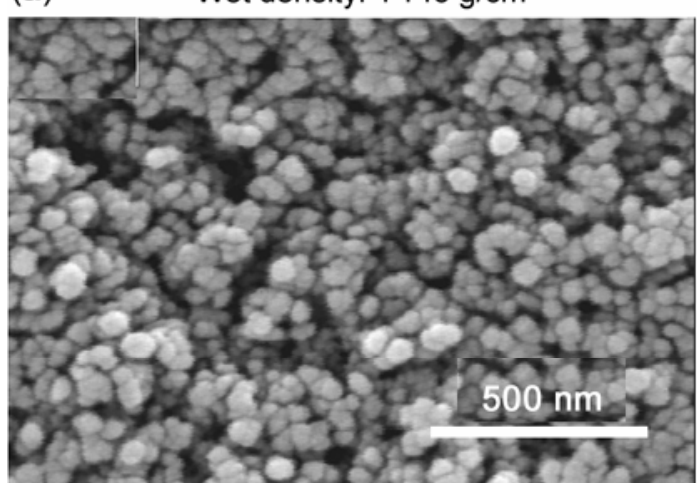

(c)

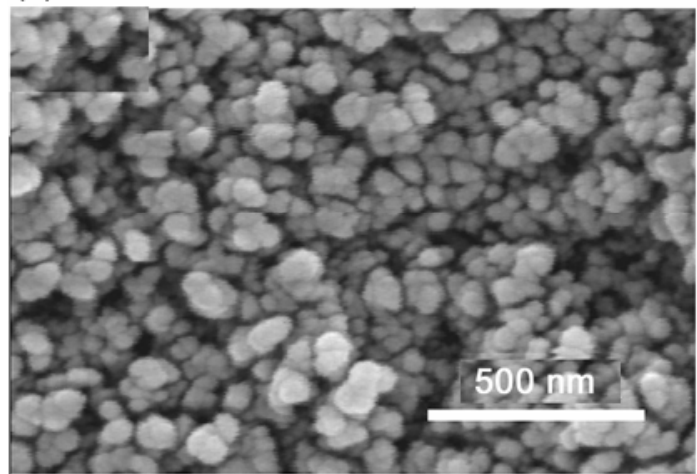

(e)

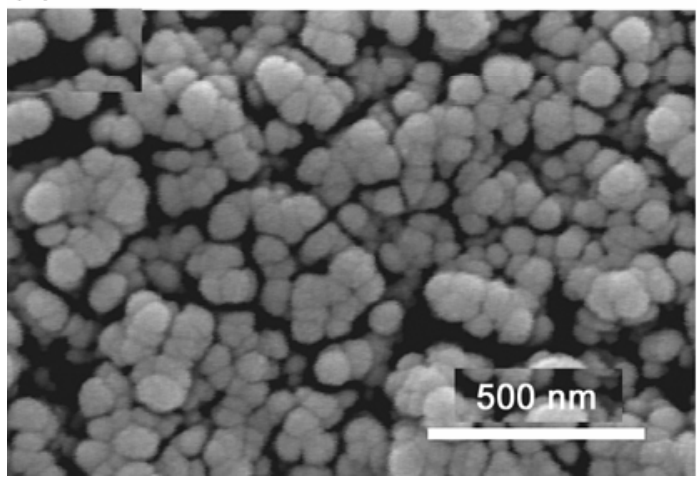

(b)

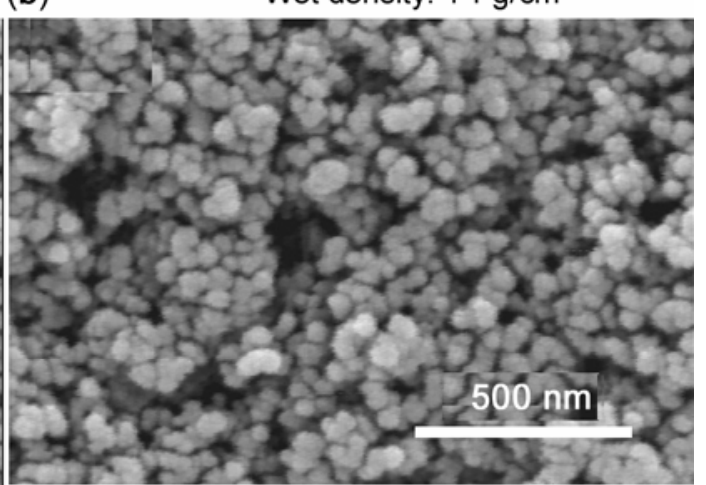

(d)

Wet density: $1.211 \mathrm{~g} / \mathrm{cm}^{3}$

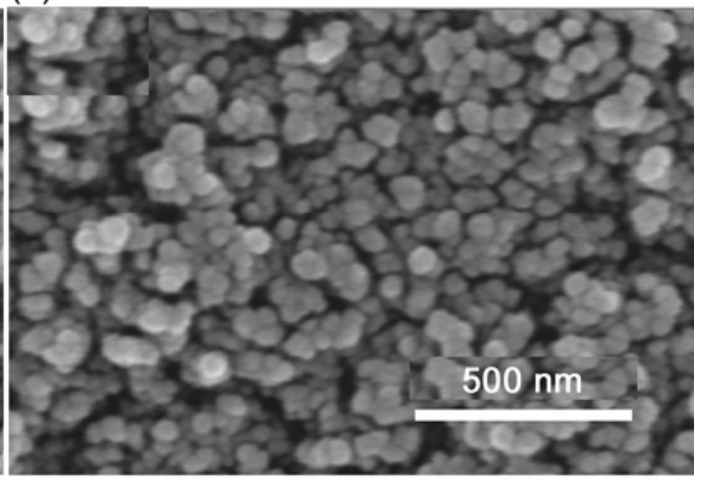

(f)

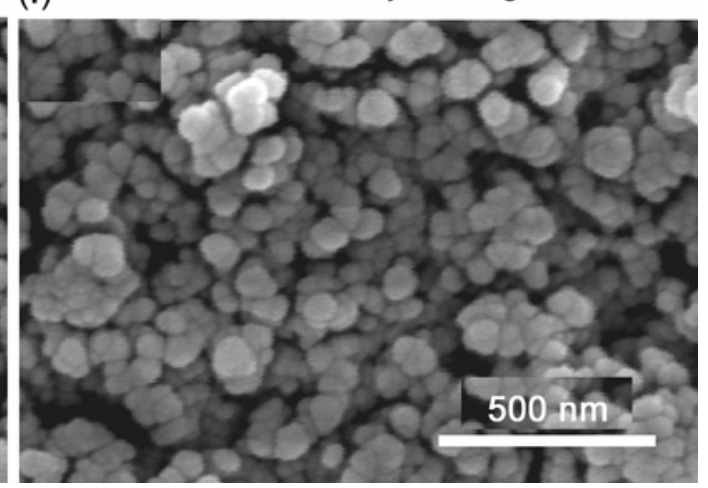

Figure 4. SEM images of deposits formed at $60 \mathrm{~V}$ and $30 \mathrm{~s}$ from the suspensions with (a) 0 , (b) $0 \cdot 33$, (c) $1 \cdot 33$, (d) 4 , (e) 8 and (f) $16 \cdot 33 \mathrm{~mL} / \mathrm{L} \mathrm{TEA}$.

are more closely packed in the deposit formed from the suspension with $4 \mathrm{~mL} / \mathrm{L}$ TEA than those deposited from other suspensions. Also, it can be seen that the microstructure of the deposits formed from the suspensions with 8 and $16.33 \mathrm{~mL} / \mathrm{L}$ TEA is highly agglomerated due to the lower zeta potential of titania nanoparticles in them (34.16 and $33.56 \mathrm{mV}$, respectively).

SEM images of the coatings deposited at 60 and $200 \mathrm{~V}$ during 15 and $60 \mathrm{~s}$ from the suspension with $0.33 \mathrm{~mL} / \mathrm{L}$ TEA are shown in figure 5. As can be seen in figure 5, SEM images are in good agreement with the results obtained for the wet density of deposits; so that at both 60 and $200 \mathrm{~V}$, the particles are more closely packed in the deposits formed during $60 \mathrm{~s}$ than $15 \mathrm{~s}$. It can be seen that the deposit formed at $200 \mathrm{~V}$ for $60 \mathrm{~s}$ have the most closely packed microstructure; also it can be seen that the microstructure of this deposit has coarser particles. The coarser particles need higher driving force for movement as well as longer time for reaching the substrate (Meng et al 2006). The driving force for the migration of coarser particles is enough at larger applied voltages. Since, coarser particles move more slowly than finer particles, therefore, it takes longer time for coarser particles to reach the substrate electrode. These result in the coarser microstructure at larger applied voltages and longer EPD times. 
(a)

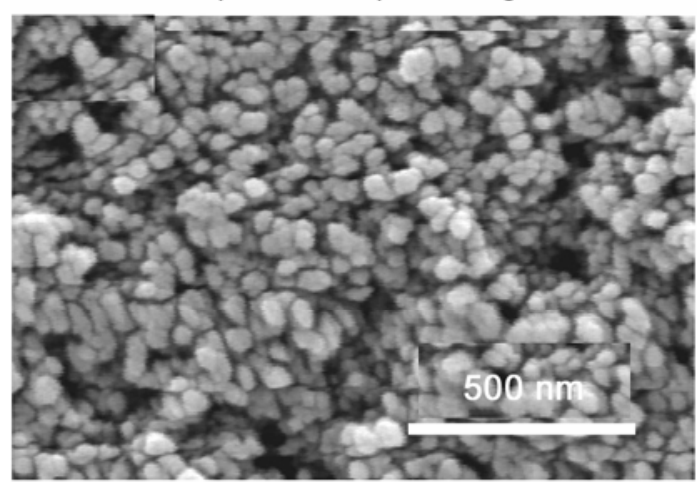

(c)

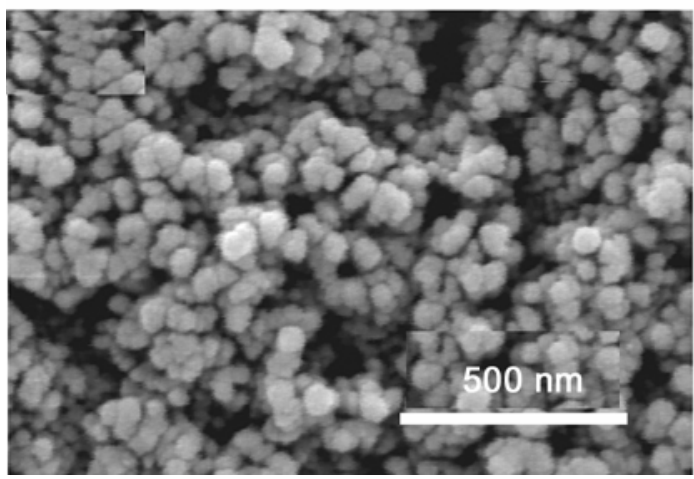

(b) $\quad(60 \mathrm{~V}, 60 \mathrm{~s}), 1.024 \mathrm{~g} / \mathrm{cm}^{3}$

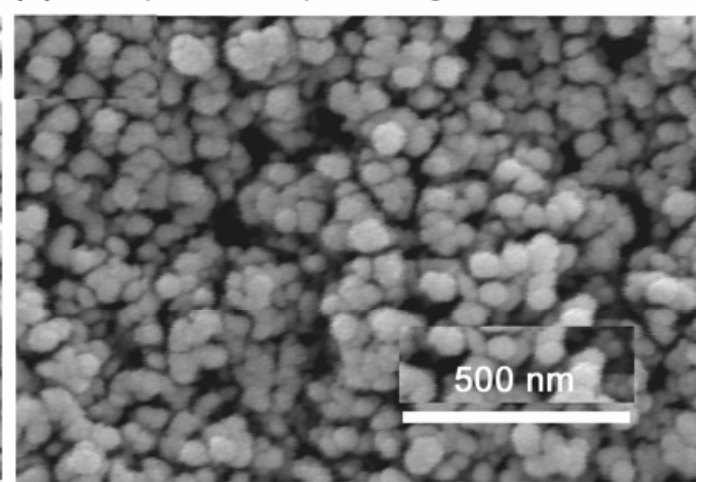

(d)

(200 V, $60 \mathrm{~s}), 1.236 \mathrm{~g} / \mathrm{cm}^{3}$

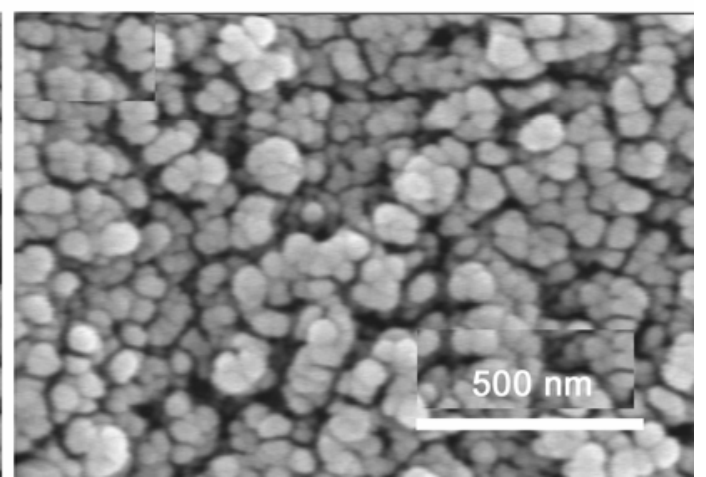

Figure 5. SEM images of deposits formed at 60 (a, b) and $200 \mathrm{~V}(\mathbf{c}, \mathbf{d})$ during 15 (a, c) and $60 \mathrm{~s}(\mathbf{b}, \mathbf{d})$ from the suspension with $0.33 \mathrm{~mL} / \mathrm{L}$ TEA.

(a) Wet density: $1.05 \mathrm{~g} / \mathrm{cm}^{3}$

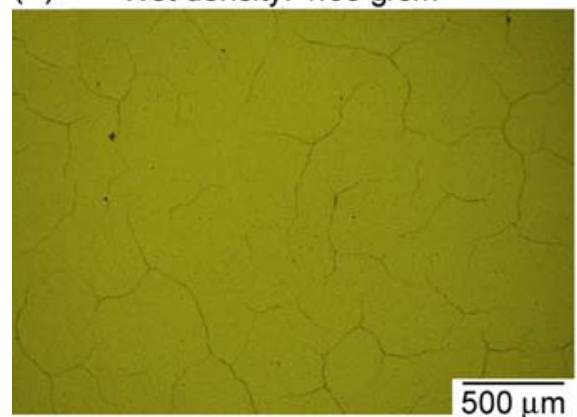

(b) Wet density: $1.11 \mathrm{~g} / \mathrm{cm}^{3}$

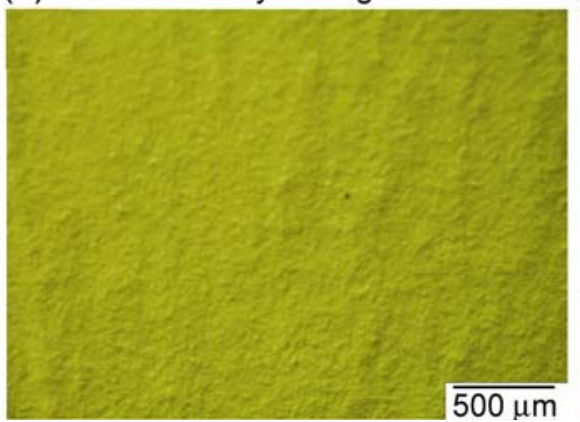

(c) Wet density: $1.00 \mathrm{~g} / \mathrm{cm}^{3}$

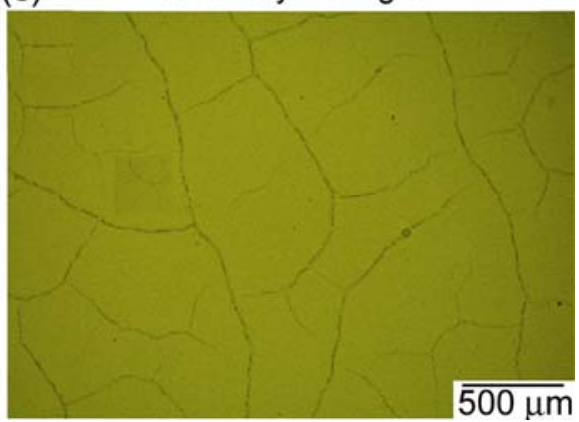

Figure 6. Optical microscope images of the coatings deposited at $60 \mathrm{~V}$ for $60 \mathrm{~s}$ from the suspensions with (a) 0 , (b) 4 and (c) $16.33 \mathrm{~mL} / \mathrm{L}$ TEA (the thickness of the dry deposits was nearly equal to $\approx 40 \mu \mathrm{m}$ ).

The optical microscopic images of the coatings deposited at $60 \mathrm{~V}$ for $60 \mathrm{~s}$ from the suspensions with 0,4 and $16.33 \mathrm{~mL} / \mathrm{L}$ TEA are shown in figure 6 . As can be seen, the coatings deposited from the suspensions with 0 and $16.33 \mathrm{~mL} / \mathrm{L}$ TEA have some small cracks, while that deposited from the suspension with $4 \mathrm{~mL} / \mathrm{L}$ TEA does not have any crack. Large shrinkages induced during drying exert the mechanical stresses on the coatings resulting in their cracking. The larger the wet density of the deposit, the smaller the volume of liquid phase, which should be removed during drying; this causes in the smaller drying shrinkages for the deposits with larger wet densities and so the smaller mechanical stresses exerted on them during drying. The wet density of the coating deposited at $60 \mathrm{~V}$ for $60 \mathrm{~s}$ from the suspension with $4 \mathrm{~mL} / \mathrm{L}$ TEA is higher than those deposited from the suspensions with 0 and $16.33 \mathrm{~mL} / \mathrm{L}$ TEA resulting in its smaller drying shrinkage, so that cracking does not occur in it. However, some cracks are generated during the drying of the coatings deposited from the suspensions with 0 and $16.33 \mathrm{~mL} / \mathrm{L}$ 


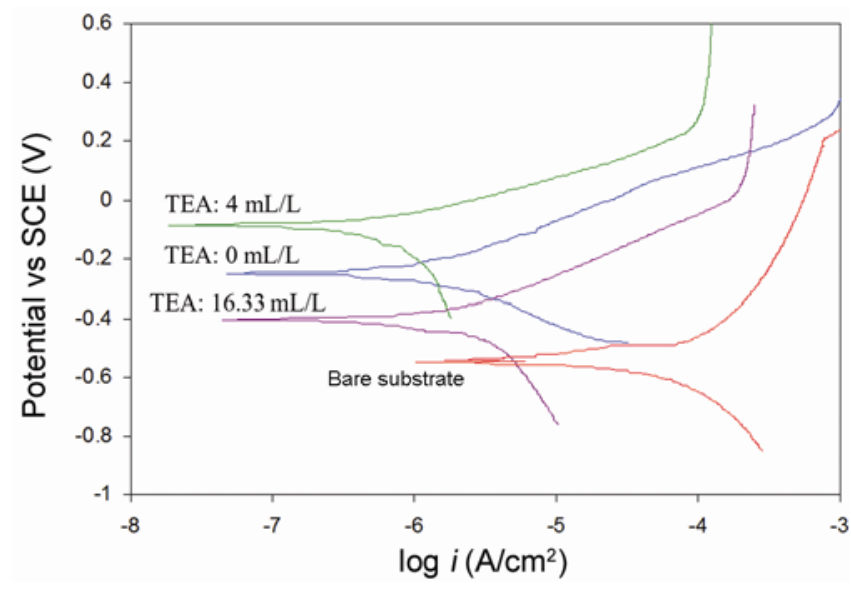

Figure 7. Polarization curves for bare stainless steel substrate and those coated with titania at $60 \mathrm{~V}$ for $60 \mathrm{~s}$ from the suspensions with different concentrations of TEA in Ringer's solution at $37.5{ }^{\circ} \mathrm{C}$.

Table 2. Corrosion current density $\left(i_{\text {corr }}\right)$ and potential $\left(E_{\text {corr }}\right)$ for bare stainless steel and substrates coated from the suspensions with different concentrations of TEA in Ringer's solution at $37 \cdot 5{ }^{\circ} \mathrm{C}$.

\begin{tabular}{lcc}
\hline Specimen & $i_{\text {corr }}\left(\mu \mathrm{A} / \mathrm{cm}^{2}\right)$ & $E_{\text {corr }}(\mathrm{mV})$ \\
\hline Bare substrate & $30 \cdot 33$ & -546 \\
TEA: $0 \mathrm{~mL} / \mathrm{L}$ & 1.20 & -249 \\
TEA: $4 \mathrm{~mL} / \mathrm{L}$ & $0 \cdot 51$ & -64 \\
TEA: $16.33 \mathrm{~mL} / \mathrm{L}$ & 1.58 & -405 \\
\hline
\end{tabular}

TEA (it must be mentioned that the dry thickness of these deposits was nearly equal $(\approx 40 \mu \mathrm{m}$, figure 3$)$, so that the effect of thickness on the crack formation has been eliminated).

The polarization curves for bare stainless steel substrate and those coated with titania at $60 \mathrm{~V}$ for $60 \mathrm{~s}$ from the suspensions with 0,4 and $16.33 \mathrm{~mL} / \mathrm{L}$ TEA in Ringer's solution at $37.5{ }^{\circ} \mathrm{C}$ are shown in figure 7 . The corrosion current density $\left(i_{\text {corr }}\right)$ and potential $\left(E_{\text {corr }}\right)$ obtained from these curves are listed in table 2. The corrosion rate of substrate decreases as it is coated with titania indicating that titania acts as a effective barrier layer against the diffusion of corrosive fluid towards the bare substrate. The coating deposited from the suspension with $4 \mathrm{~mL} / \mathrm{L}$ TEA has the lowest $i_{\text {corr }}$ and the highest $E_{\text {corr }}$ and so the best corrosion resistance due to its higher packing density and crack free microstructure (figure 6b). The cracks in the coatings deposited from the suspensions with 0 and $16.66 \mathrm{~mL} / \mathrm{L}$ TEA (figure $6 \mathrm{a}, \mathrm{c}$ ) act as the short diffusion paths for corrosive fluid to reach the metal surface and corrode it.

\section{Conclusions}

The suspensions of titania nanoparticles were prepared in isopropanol using triethanolamine as the dispersant.
Electrophoretic deposition was performed at 60 and $200 \mathrm{~V}$ for 15, 30, 60, 120, 240 and $360 \mathrm{~s}$; the wet density of deposits was determined against EPD time; results showed that the wet density increases with time at both voltages (faster at $200 \mathrm{~V}$ ) and attains a plateau at longer times. Electric field over the deposits (and so the velocity of electro-osmotic flow) showed a similar behaviour as the wet density. It was found that the velocity at which particles attach to the deposit is very important in determining the wet density at initial times of EPD; while the velocity of electro-osmotic flow around the particles in deposit becomes more important at longer EPD times. The microstructure of deposits observed by SEM had a good agreement with the results calculated for their wet density. It was found that the coating deposited from the suspension with $4 \mathrm{~mL} / \mathrm{L}$ TEA has the higher corrosion resistance in Ringer's solution at $37.5{ }^{\circ} \mathrm{C}$ due to its closely packed and crack-free microstructure.

\section{References}

Agrafiotis C and Tsetsekou A 2002 J. Eur. Ceram. Soc. 22423

Basu R N, Randall C A and Mayo M J 2001 J. Am. Ceram. Soc. 8433

Besra L and Liu M 2007 Progr. Mater. Sci. 521

Bohmer M 1996 Langmuir 125747

Cook S D, Thomas K A, Delton J E, Volkman T K, Whitecloud III Th S and Key J F 1992 J. Biomed. Mater. Res. 26989

Farrokhi-Rad M and Ghorbani M 2011 J. Am.Ceram. Soc. 94 2354

Farrokhi-Rad M and Shahrabi T 2012 J. Am. Ceram. Soc. 953434

Grinis L, Dor S, Ofir A and Zaban A 2008 J. Photochem. Photobiol. A: Chem. 19852

Hench L L 1998 J. Am. Ceram. Soc. 811705

Ji Ch, Lan W and Xiao P 2008 J. Am. Ceram. Soc. 911102

Kawakita M, Uchikoshi T, Kawakita J and Sakka Y 2009 J. Am. Ceram. Soc. 92984

Kienapfel H, Sprey C, Wilke A and Griss P 1999 J. Arthroplasty 14355

Kulkarni A, Gutleber J, Sampath S, Goland A, Lindquist W B, Herman H, Allen A J and Dowd B 2004 Mater. Sci. Eng. A369 124

Meng X, Kwon T Y, Yang Y, Ong J L and Kim K H 2006 J. Biomed. Mater. Res. B: Appl. Biomater. 78373

Nguyen H Q, Deporter D A, Pilliar R M, Valiquette N and Yakubovich R 2004 Biomaterials 25865

Smoluchowski M V 1917 Z. Phys. Chem. 92129

Solomentsev Y, Bohmer M and Anderson J L 1997 Langmuir 136058

Tang F, Uchikoshi T, Ozawa K and Sakka Y 2006 J. Eur. Ceram. Soc. 261555

Yeh S R, Seul M and Shraiman B I 1997 Nature 38657

Yui T, Mori Y, Tsuchino T, Itoh T, Hattori T, Fukushima Y and Takagi K 2005 Chem. Mater. 17206

Yu J, Zhao X, Du J and Chen W 2000 J. Sol-Gel Sci. Technol. 17163

Yusuf M M, Imai H and Hirashima H 2002 J. Sol-Gel Sci. Technol. 2565 